\title{
Accumulation of Common Clonal T Cells in Multiple Lesions of Sarcoidosis
}

\author{
Toshiyuki Sawabe, ${ }^{1,2}$ Satoshi Shiokawa, ${ }^{1}$ Katsunori Sugisaki, $^{2}$ \\ Tomiyasu Tsuda, ${ }^{2}$ Kazuhiko Yamamoto ${ }^{3}$ \\ ${ }^{1}$ Department of Clinical Immunology, Medical Institute of Bioregulation, \\ Kyushu University, Beppu, Japan \\ ${ }^{2}$ Third Department of Internal Medicine, Oita Medical University, Oita, Japan \\ ${ }^{3}$ Department of Allergy and Rheumatology, Faculty of Medicine, University \\ of Tokyo, Tokyo, Japan \\ Accepted May 25, 2000.
}

\begin{abstract}
Background: $\mathrm{T}$ cells recognizing as yet unknown antigens (Ags) are considered to play an important role in the development and perpetuation of the disease process of sarcoidosis. Several studies have shown that $\mathrm{T}$ cells that bear a limited T-cell receptor (TCR) repertoire may play an important role in this disorder. However, regarding variable (V) gene repertoire usage, the results differ among various reports. One reason for such inconsistency may be due to the materials used in these studies. Most studies analyzed the T-cell repertoire in the sarcoid lung. However, clonal expansion of pulmonary $\mathrm{T}$ cells, probably due to the activation by inhaled exogenous Ags, was observed and such expansion may seriously influence the repertoire analysis.

Materials and Methods: Reverse transcriptasepolymerase chain reaction and subsequent single-
\end{abstract}

strand conformation polymorphism analysis were used for the analysis of TCR repertoire. To exclude unrelated T-cell clones, we used intramuscular sarcoid nodules and/or lymph node (LN) sarcoid lesions as our materials. We also analyzed sarcoid lesions from different organs and then compared the results.

Results: T cells of the same clonality were found to exist in widely separated sites in intramuscular and LN sarcoid lesions in almost all $\mathrm{V} \beta$ subfamilies. Identical T-cell clones were present in the sarcoid lesions from different organs in several $\mathrm{V} \beta$ subfamilies.

Conclusions: Some of the common T-cell clones in separated sites in intramuscular and LN sarcoid lesions and in sarcoid samples from different organs may recognize Ags that are related to the pathogenesis of sarcoidosis.

\section{Introduction}

Sarcoidosis is a systemic, nonmalignant disorder that is histologically defined by the presence of noncaseating granulomas in the involved tissues (1). Granuloma formation follows the accumulation of large numbers of $\mathrm{T}$ lymphocytes within the lesions (2). These $\mathrm{T}$ cells

Address correspondence and reprint requests to: Satoshi Shiokawa, M.D., Ph.D., Department of Clinical Immunology, Medical Institute of Bioregulation, Kyushu University, Tsurumihara 4546, Beppu, Oita 874-0838, Japan. Phone: +81-977-27-1640; Fax: +81-977-27-1641 predominantly demonstrate a $\mathrm{CD} 4^{+}$phenotype (3) and a subset of these cells express surface markers of activation (4-6). In addition, the close parallels of sarcoidosis with granulomatous diseases of known etiology, such as tuberculosis, leprosy, and chronic beryllium disease, suggest that antigen $(\mathrm{Ag})$-specific $\mathrm{T}$ cells play an important role in the development and perpetuation of the disease process (7-9).

To understand the nature of the stimulus that results in the accumulation of $\mathrm{T}$ cells at disease sites, several groups examined the $\mathrm{T}$ cell receptor (TCR) repertoire of $\mathrm{T}$ cells 
isolated from the lungs of sarcoidosis patients. Concerning variable $(\mathrm{V})$ gene usage in sarcoid lung, several studies have been reported, with varying results (10-23). Such inconsistency may be due to a difference in the genetic background of the subjects or to some difference in the causative Ags of sarcoidosis among different areas. In addition, although these studies used bronchoalveolar lavage (BAL) as the materials, the clonal expansion of $\mathrm{T}$ cells, which was probably due to the activation by the inhaled exogenous Ags, was observed even in BAL samples from normal healthy individuals (24). Another problem comes from methodologic limitations. Till now, the analysis of TCR $\mathrm{V}$ gene repertoire usage was conducted using monoclonal antibodies to a certain $\mathrm{V}$ gene subfamily element or polymerase chain reaction (PCR) using a set of primers specific to each $\mathrm{V}$ gene subfamily element (10-23). In such cases, T-cell expansion could not be well-investigated at the clonal level. In this study, we used a different strategy to overcome these limitations and analyzed the clonal nature of $\mathrm{T}$ cells in the sarcoid lesions.

\section{Materials and Methods}

Study Populations

The diagnosis of sarcoidosis was made in 10 individuals, based on the appropriate clinical features. The diagnosis was confirmed by a biopsy obtained from the lungs and/or lymph nodes (LNs) and showing noncaseating epithelioid granulomas. All patients had a chronic active disease. The characteristics of the patients studied are shown in Table 1. In five patients, intramuscular nodules were present and in six patients, a scalene LN biopsy was performed. Mainly samples from intramuscular and scalene LN sarcoid lesions were analyzed in this study. None of the patients had received corticosteroid or other immunosuppressive medications before the study. Informed consent was obtained from all patients and the healthy individuals.

\section{Reverse Transcriptase (RT)-PCR Single-strand Conformation Polymorphism (SSCP) Analysis}

The total RNA was extracted from each sample and reverse-transcribed into cDNA. The cDNA was then amplified by PCR with a combination

Table 1. Patient profiles

\begin{tabular}{|c|c|c|c|c|c|c|c|}
\hline \multirow[b]{2}{*}{ Patient } & \multirow[b]{2}{*}{ Sex } & \multirow[b]{2}{*}{ Age } & \multirow[b]{2}{*}{$\begin{array}{l}\operatorname{Serum~ACE}^{a} \\
(6.0-21.0 \mathrm{IU} / \mathrm{L})\end{array}$} & \multicolumn{3}{|c|}{$\mathbf{B A L} \mathbf{L}^{\mathbf{b}}$} & \multirow[b]{2}{*}{$\begin{array}{c}\text { Tissue Specimens Analyzed } \\
\text { in this Study }\end{array}$} \\
\hline & & & & $\begin{array}{l}\text { Total Cell } \\
\left(\times 10^{5} / \mathrm{ml}\right)\end{array}$ & $\begin{array}{l}\text { \%lymphocyte } \\
\text { Count }\end{array}$ & $\mathrm{CD} 4 / 8$ & \\
\hline 1 & $\mathrm{~F}$ & 60 & 35.2 & 2.5 & 43 & 7.23 & $\begin{array}{l}\text { PBMC }^{\mathrm{C}} \text {, muscular sarcoid } \\
\text { lesion (right crus) }\end{array}$ \\
\hline 2 & F & 58 & 21.0 & 1.5 & 4.5 & 5.00 & $\begin{array}{l}\text { PBMC, muscular sarcoid } \\
\text { lesion (left crus) }\end{array}$ \\
\hline 3 & F & 39 & 9.8 & 1.0 & 28 & 3.47 & $\begin{array}{l}\text { PBMC, muscular sarcoid } \\
\text { lesion (left crus) }\end{array}$ \\
\hline 4 & $\mathbf{M}$ & 35 & 16.9 & 10.0 & 12 & 7.09 & $\begin{array}{l}\text { PBMC, muscular sarcoid } \\
\text { lesion (right femur), TBLB }\end{array}$ \\
\hline 5 & $\mathbf{M}$ & 70 & 12.1 & 2.0 & 21 & 11.14 & $\begin{array}{l}\text { PBMC, muscular sarcoid } \\
\text { lesion (left crus), } \mathrm{LN}^{\mathrm{d}}\end{array}$ \\
\hline 6 & $\mathbf{M}$ & 36 & 5.2 & 2.0 & 30 & 1.58 & PBMC, LN \\
\hline 7 & $\mathbf{M}$ & 68 & 15.0 & 1.0 & 13 & 6.59 & PBMC, LN \\
\hline 8 & $\mathrm{~F}$ & 69 & 6.0 & 1.5 & 19 & 6.07 & PBMC, LN \\
\hline 9 & F & 47 & 19.3 & 1.5 & 15 & 4.46 & PBMC, LN \\
\hline 10 & $\mathbf{M}$ & 55 & 16.8 & 1.5 & 19 & 6.81 & PBMC, LN \\
\hline
\end{tabular}

${ }^{\mathrm{a}} \mathrm{ACE}$, angiotensin converting enzyme; ${ }^{\mathrm{b}} \mathrm{BAL}$, bronchoalveolar lavage; ${ }^{\mathrm{c}} \mathrm{PBMC}$, peripheral blood mononuclear cells; ${ }^{\mathrm{d}} \mathrm{LN}$, lymph nodes; ${ }^{\mathrm{e} T B L B}$, transbronchial lung biopsy. 
of a $\mathrm{C} \beta$ primer and each of $22 \mathrm{~V} \beta$-specific primers (25). After 35 cycles of PCR $\left(94^{\circ} \mathrm{C}\right.$ for $1.5 \mathrm{~min}, 60^{\circ} \mathrm{C}$ for $2 \mathrm{~min}, 72^{\circ} \mathrm{C}$ for $\left.3 \mathrm{~min}\right)$, the amplified DNA was diluted (1:20) in a denaturing solution $(95 \%$ formamide, $10 \mathrm{mM}$ EDTA, $0.1 \%$ bromophenol blue, and $0.1 \%$ xylene cyanol) and then was maintained at $90^{\circ} \mathrm{C}$ for $2 \mathrm{~min}$. The diluted sample $(2 \mu \mathrm{l})$ was electrophoresed in nondenaturing $5 \%$ polyacrylamide gels containing $10 \%$ glycerol, at $35 \mathrm{~W}$ of constant power, and at $25^{\circ} \mathrm{C}$ constant temperature for approximately $2 \mathrm{hr}$. The DNA was then transferred to Immobilon-S (Millipore Intertech, Bedford, MA), hybridized with a biotinylated $\mathrm{C} \beta$ probe (5'-biotinA(AC)AA(GC) GTGTTCCCGAGGTCGCTGTGTT-3') at $42^{\circ} \mathrm{C}$ for $12 \mathrm{hr}$, washed for $10 \mathrm{~min}$ at $55^{\circ} \mathrm{C}$, and then visualized by subsequent incubations with streptavidin, biotinylated alkaline phosphatase, and a chemiluminescent substrate system (Phototope detection kit, New England Biolabs, Beverly, MA).

\section{Sequence Analysis of Clonal Bands}

A small area of dried SSCP gel corresponding to the position of the band was cut out. The gel piece was immersed in $50 \mu \mathrm{l}$ of TE (10 $\mathrm{mM}$ Tris- $\mathrm{HCl} / 0.1 \mathrm{mM}$ EDTA) in a microcentrifuge tube and was heated at $80^{\circ} \mathrm{C}$ for 20 min. The extract was vortexed and centrifuged. The supernatant $(5 \mu \mathrm{l})$ was then reamplified for 35 cycles with the same $\mathrm{V} \beta$ specific primers and constant region primers used in RT-PCR, except that they had a $X b a I$ and EcoRI cutting site, respectively, and were purified from $1.1 \%$ agarose gel. The recovered DNA fragments were ligated in the XbaI/ EcoRI site of pBluescript SK - (Stratagene, La Jolla, CA) and then were used to transform Escherichia coli strain XL-1Blue (Stratagene, La Jolla, CA). The clones were picked randomly and a double-strand DNA template was prepared and sequenced using the DyeDeoxy Terminator Cycle Sequencing kit and the Applied Biosystems automatic DNA sequencer (Applied Biosystems, Riossy, France).

\section{Results}

RT-PCR-SSCP Analysis of V $\beta$ Gene Expressions

Biopsy specimens from the 10 sarcoidosis patients were subjected to a RT-PCR-SSCP analysis to investigate the T-cell clonotypes. In the RT-PCR-SSCP analysis, a heterogeneous T-cell population, such as peripheral blood mononuclear cells (PBMCs) from healthy individuals, was shown to exhibit a smear pattern, because the complementarity determining region (CDR)3 of TCR was diverse. A single T-cell clone makes a band. In contrast, a band can be observed in the smear if there is an expanded T-cell clonotype in a heterogeneous population (26-31).

\section{TCR Clonotype Analysis of Intramuscular Sarcoid Lesions}

Although most $\mathrm{T}$ cell clonality studies previously used BAL as materials, it is known that marked clonal expansion of $\mathrm{T}$ cells, probably due to the activation by inhaled exogenous Ags, is observed even in BAL samples from normal healthy individuals (24). Therefore, TCR V gene repertoire of lung $\mathrm{T}$ cells should be strongly influenced by the patient profile, including such factors as occupation, living conditions, habits, as well as a past history of respiratory diseases. To minimize the effect of T-cell clones activated by Ags that were not related to the pathogenesis of sarcoidosis, we first analyzed biopsy samples from intramuscular sarcoid lesions. Half of each intramuscular nodule was used for a histological analysis. In all patients, the nodules were largely occupied with noncaseating epithelioid cell granuloma. The other half was used for the RT-PCR-SSCP analysis. The results of the RT-PCR-SSCP analysis of intramuscular sarcoid lesions from patient 1 are shown in Figure 1A. Although the results of $\mathrm{V} \beta 1-10$ were shown, similar results were also obtained for $\mathrm{V} \beta 11-20$. PBMCs mainly exhibited smear patterns. In contrast, two separate regions of the intramuscular sarcoid lesion showed distinct bands of the same mobility on the smears. These bands were observed in most of the $\mathrm{V} \beta$ families and were not restricted to certain $\mathrm{V} \beta$ families. The results of the analysis of intramuscular sarcoid lesions from patients 2-5 were similar to those from patient 1 . The results of $v \beta 3,5.2,7$ and 9 analyses of patients 2 and 3 are shown in Figure 1B. The results of $\mathrm{V} \beta 4,6,7,9-11,15$ and 20 analyses of patients 4 and $\mathrm{V} \beta 2-4$ and 9 analyses of patient 5 are presented in Figure 3. We also performed a RT-PCR-SSCP analysis of paravertebral muscle specimens that were obtained during fenestration from two patients with lumbar spinal canal stenosis. Although several distinct bands were observed in most $\mathrm{V} \beta$ families, muscle specimens that originated from separate portions showed a different 
A.

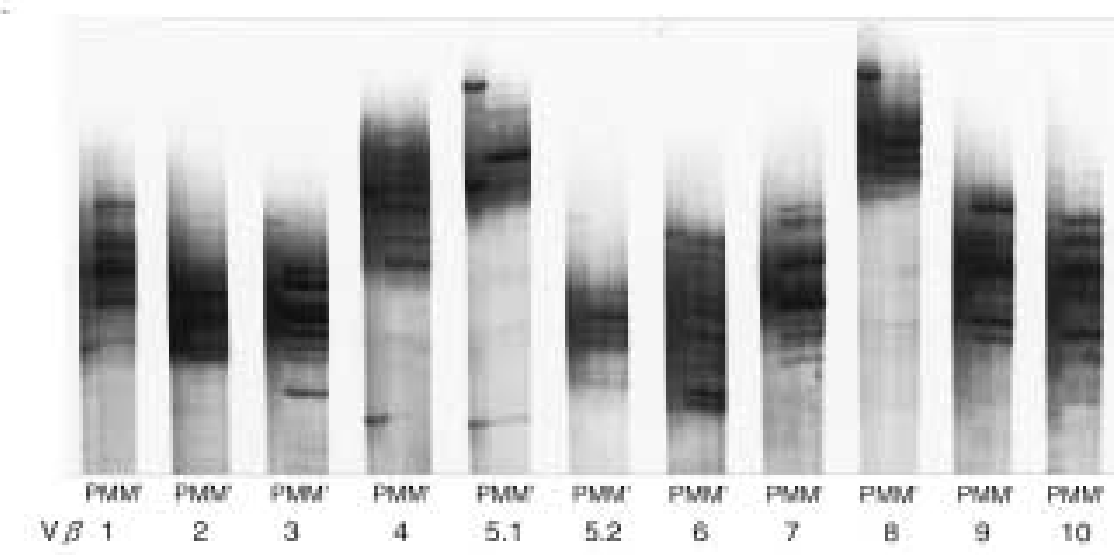

B.
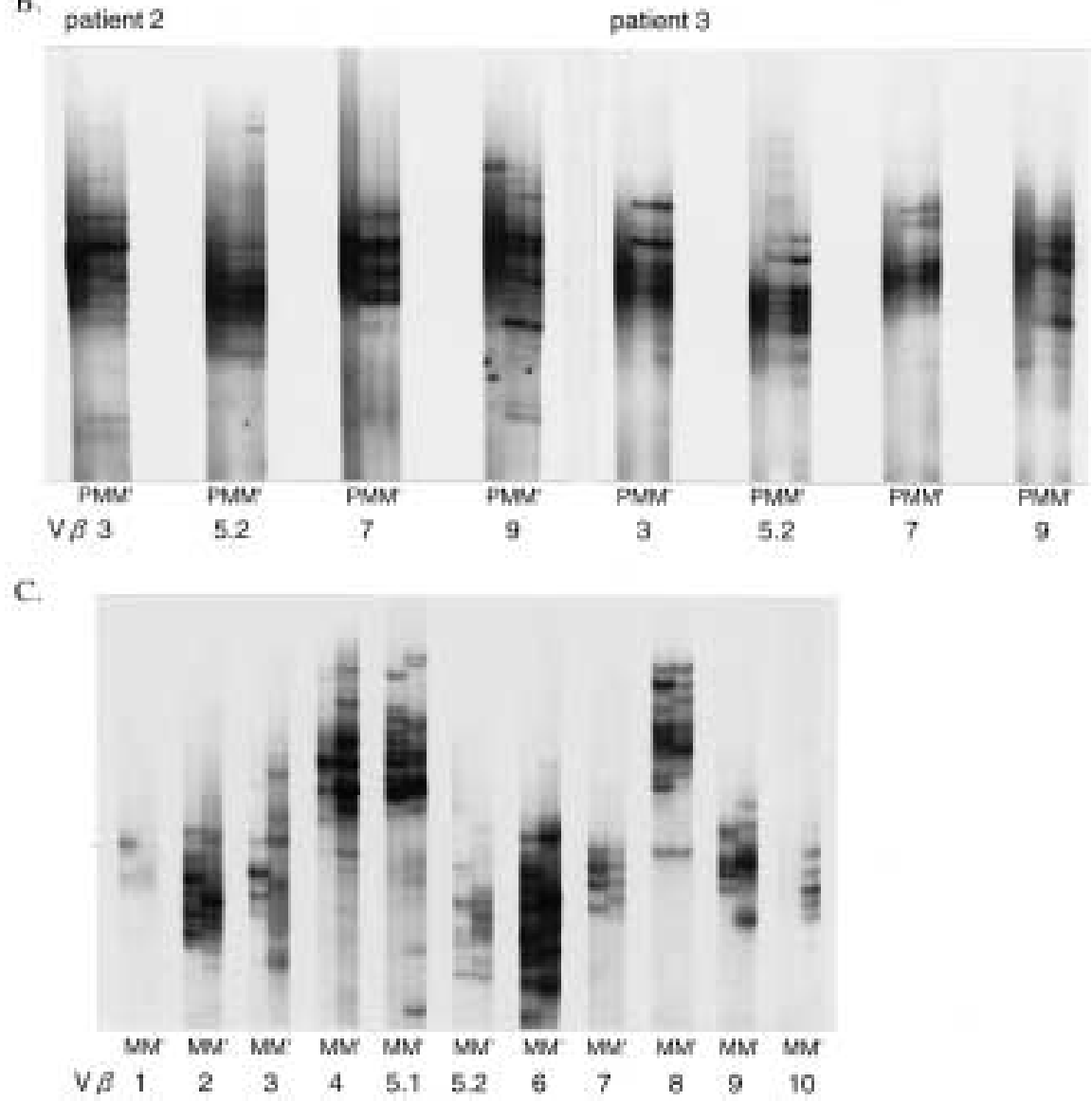

Fig. 1. A representative result of a RT-PCR-SSCP analysis of an intramuscular sarcoid lesion.

(A) Two samples from different, widely separated sites in the intramuscular sarcoid lesion $\left(\mathbf{M}, \mathbf{M}^{\prime}\right)$ and PBMCs (P) were analyzed in patient 1. PBMCs exhibit mainly smear patterns. In contrast, two separate regions of the intramuscular sarcoid lesion show distinct bands of the same mobility on the smears. (B) $\mathrm{V} \beta 3,5.2,7$ and 9 subfamily analyses of the intramuscular sarcoid lesion $\left(\mathrm{M}, \mathrm{M}^{\prime}\right)$ and PBMCs
(P) in patients 2 and 3 are presented. The results of the analysis are similar to those from patient 1 . (C) Two samples from widely separated sites in the normal muscle specimen $\left(\mathbf{M}, \mathbf{M}^{\prime}\right)$ were analyzed as a control study. Although several distinct bands are observed in most $\mathrm{V} \beta$ families, muscle specimens from two separate portions show a different migration pattern. RT-PCR-SSCP, reverse transcriptase-polymerase chain reaction-single-strand confirmation polymorphism; PBMCs, peripheral blood mononuclear cells. 
A.

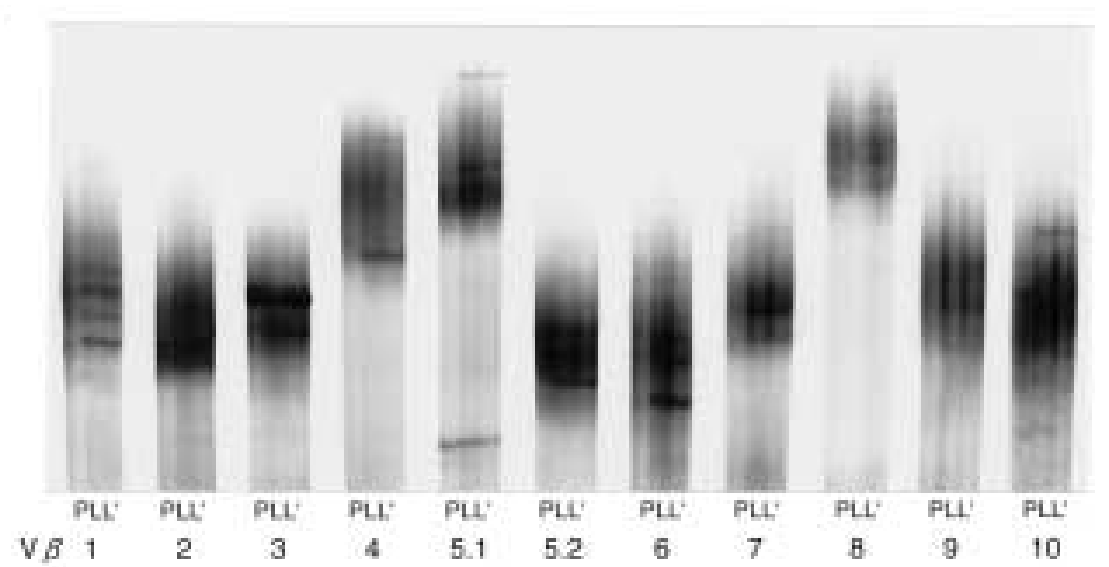

B.

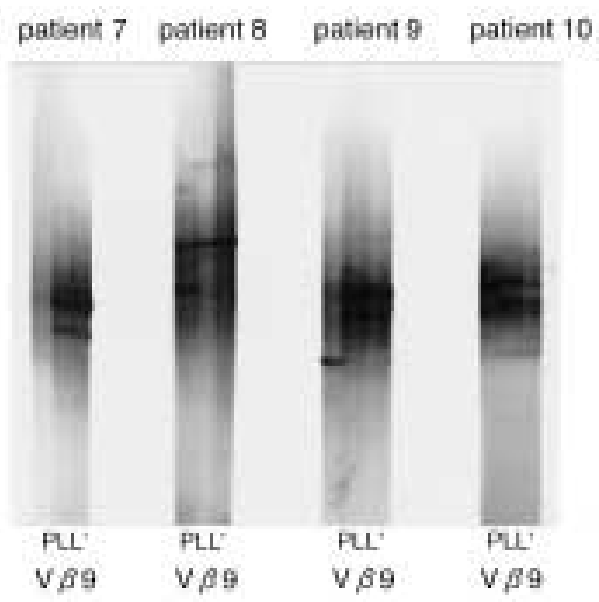

C.

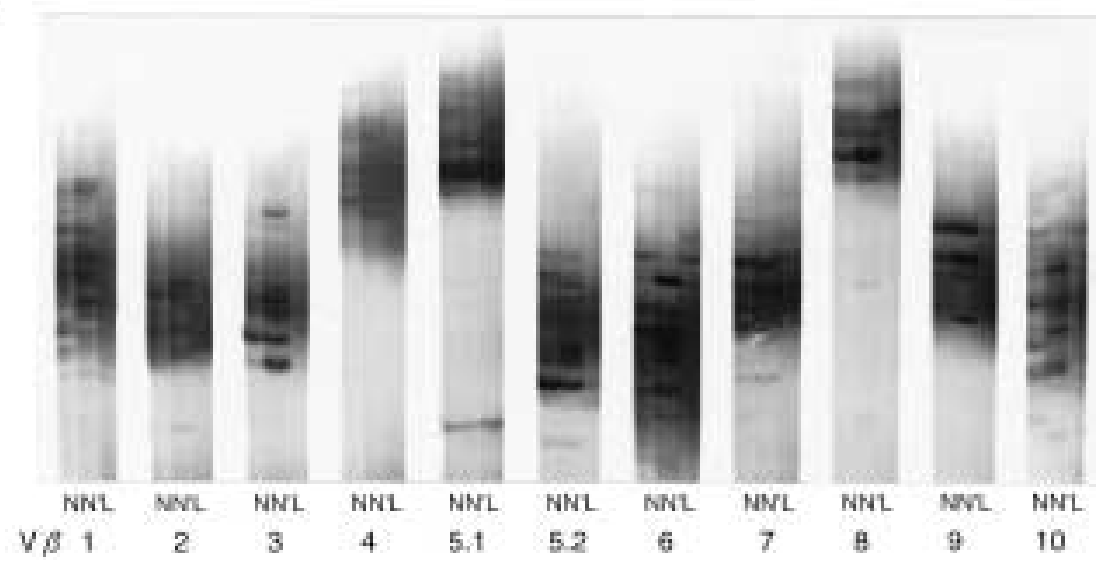

Fig. 2. The representative results of a RT-PCRSSCP analysis of a LN sarcoid lesion. (A) Two samples derived from widely separated sites in the lesion $\left(\mathrm{L}, \mathrm{L}^{\prime}\right)$ and PBMCs $(\mathrm{P})$ were analyzed in patient 6 . Several distinct bands are observed in most $\mathrm{V} \beta$ families and most of the bands in two specimens derived from separate portions of a LN sarcoid lesion show an identical migration pattern. PBMCs exhibit mainly smear patterns. (B) V $\beta 9$ subfamily analyses of LN sarcoid lesion $\left(L, L^{\prime}\right)$ and PBMCs (P) in patients 7-10 are presented. The results of the analysis are similar to those from patient 6. (C) Two samples from lung tissue samples from a patient with early stage lung cancer $\left(\mathrm{N}, \mathrm{N}^{\prime}\right)$ and a pretracheal LN sample (L) were analyzed. Lung tissue shows multiple distinct bands on the smears; whereas, the pretracheal LN node tissue exhibits mainly smear patterns. RT-PCR-SSCP, reverse transcriptase-polymerase chain reactionsingle-strand confirmation polymorphism; PBMCs, peripheral blood mononuclear cells; LN, lymph node. 
migration pattern. The results of $\mathrm{V} \beta 1-10$ analyses from one control patient are shown in Figure 1C.

\section{TCR Clonotype Analysis of LN Sarcoid Lesions}

We next performed a RT-PCR-SSCP analysis of LNs from patients 6-10. Half of each LN sample was used for a histological analysis. In all patients, the LNs were largely occupied with noncaseating epithelioid cell granuloma. The other half of each LN was used for the RT-PCR-SSCP analysis. The results of the analysis of the LN from patient 6 are shown in Figure 2A. Several distinct bands were observed in most $\mathrm{V} \beta$ families and most of the bands in two specimens derived from separate portions of the same LN showed an identical migration pattern. Although the results of $\mathrm{V} \beta 1-10$ were shown, similar results were obtained for $\mathrm{v} \beta 1 \mathrm{1}-20$ and the results of the analysis of patients 7-10 were also similar to those from patient $6 . \mathrm{V} \beta 9$ analyses of

\section{A.}

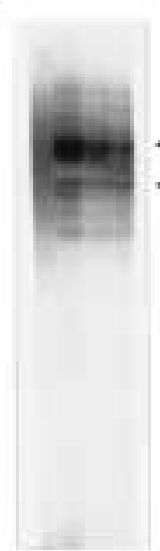

PMMT $\vee \beta 4$

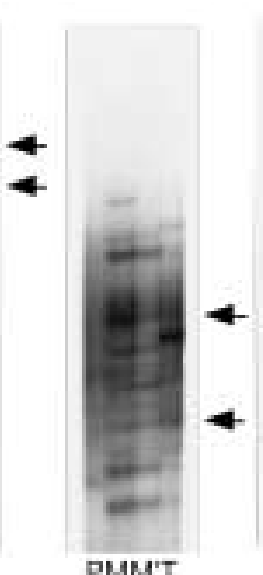

PMM'T V 86

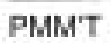
V 87
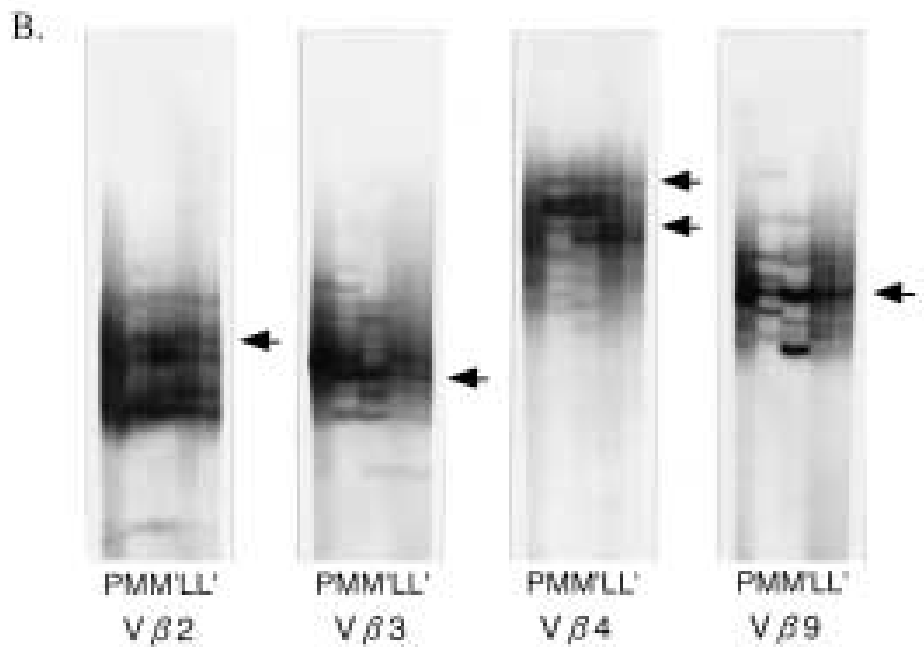

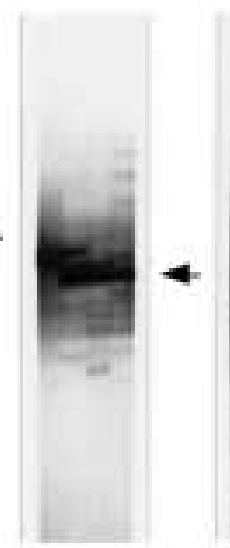

PMMT $\vee \beta 9$

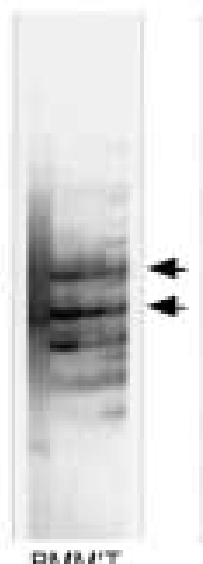

PMM'T

V $\beta 10$

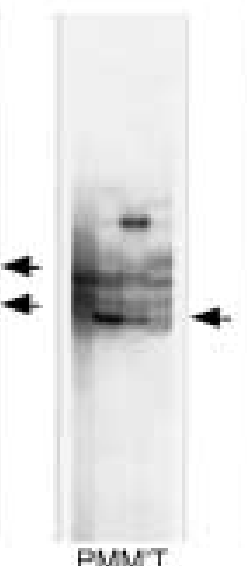

PMMT

$\mathrm{V} \beta 11$

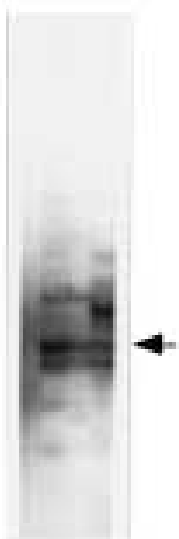

PMM'T

$\checkmark \beta 15$

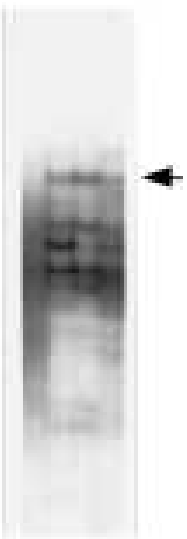

PMM'T

Fig. 3. The results of a RT-PCR-SSCP analysis of sarcoid lesions from different organs. (A) In patient 4, two samples from widely separated sites in the intramuscular sarcoid lesion $\left(M, M^{\prime}\right)$, a TBLB sample $(\mathrm{T})$ and PBMCs $(\mathrm{P})$ were analyzed. In $\mathrm{V} \beta 4,6,7,9-11,15$, and 20, several distinct bands, which are common in the TBLB sample and two samples from separate portions of an intramuscular sarcoid lesion, are observed. The arrows indicate the position of the common bands. (B) In patient 5, two samples from widely separated sites in the intramuscular sarcoid lesion

$\left(\mathrm{M}, \mathrm{M}^{\prime}\right)$ and two samples from those in $\mathrm{LN}$ sarcoid lesion $\left(\mathrm{L}, \mathrm{L}^{\prime}\right)$, and PBMCs $(\mathrm{P})$ were analyzed. In $\mathrm{V} \beta 2-4$ and 9 analyses, common distinct bands are observed in samples from separate portions of the LN and intramuscular sarcoid lesions. The arrows indicate the position of common bands. RT-PCR-SSCP, reverse transcriptase-polymerase chain reaction-singlestrand confirmation polymorphism; PBMCs, peripheral blood mononuclear cells; TBLB, transbronchial lung biopsy; LN, lymph node. 
Table 2. Amino acid sequences of the CDR3 region

\begin{tabular}{|c|c|c|c|c|c|c|}
\hline \multirow{2}{*}{$\frac{\text { Patient }}{1}$} & \multirow{2}{*}{$\begin{array}{c}\text { Sample } \\
\mathrm{MM}^{\prime}\end{array}$} & \multirow{2}{*}{$\begin{array}{c}\mathbf{V} \boldsymbol{\beta 9} \\
\text { YFCASSQ }\end{array}$} & \multirow{2}{*}{$\begin{aligned} \mathbf{N D} \boldsymbol{\beta} \mathbf{N} \\
\mathrm{AGD}\end{aligned}$} & \multicolumn{2}{|c|}{$\mathbf{J} \boldsymbol{\beta}$} & \multirow{2}{*}{$\frac{\mathbf{C} \boldsymbol{\beta}}{\mathrm{C} \beta 2}$} \\
\hline & & & & SYEQ & $\mathrm{J} \beta 2.7$ & \\
\hline 3 & $M M^{\prime}$ & YFCA & TTGTSGLG & EQFF & $\mathrm{J} \beta 2.1$ & $\mathrm{C} \beta 2$ \\
\hline 4 & MT & YFCASSQ & DPGT & PQHF & $\mathrm{J} \beta 1.5$ & $\mathrm{C} \beta 1$ \\
\hline 5 & ML & YFCASSQ & TYG & IQYF & $\mathrm{J} \beta 2.4$ & $\mathrm{C} \beta 2$ \\
\hline 7 & LL' $^{\prime}$ & YFCASS & PSQL & QETQ & $\mathrm{J} \beta 2.5$ & $\mathrm{C} \beta 2$ \\
\hline 8 & $\mathrm{LL}^{\prime}$ & YFCASS & SQQGMV & AKNI & $\mathrm{J} \beta 2.4$ & $\mathrm{C} \beta 2$ \\
\hline
\end{tabular}

patients 7-10 are shown in Figure 2B. In the LN analyses, however, distinct bands of the same mobility were sometimes present in PBMCs, as well as two separate sites of the LN sarcoid lesion (Fig. 2A, V $\beta 3$, Fig. 2B, patient 8). As a control study, we analyzed samples from a patient with early stage lung cancer without LN metastasis. Two lung tissue samples that were distant enough from the edge of the cancer and a pretracheal LN were analyzed. Lung tissue showed multiple distinct bands on the smears; whereas, the pretracheal LN node tissue exhibited mainly smear patterns (Fig. 2C). We also analyzed the axillary and inguinal LNs from two rheumatoid arthritis (RA) patients, and they were found to show smear patterns (data not shown).

\section{TCR Clonotype Analysis of Sarcoid Lesions from Different Organs}

In patient 4 , we were able to obtain three transbronchial lung biopsy (TBLB) specimens, in addition to PBMCs, and samples from intramuscular sarcoid lesions. Two TBLB specimens were histologically analyzed. Both specimens contained noncaseating epithelioid cell granulomas. The remaining TBLB sample was used for the analysis. The results of the RT-PCR-SSCP analysis are shown in Figure 3A. In $\mathrm{V} \beta 4,6,7,9-11,15$, and 20, several distinct bands, which were common in the TBLB sample and two samples from separate portions of an intramuscular sarcoid lesion, were observed. In patient 5, both LN and intramuscular sarcoid lesions were obtained. In $\mathrm{V} \beta 2-4$ and 9 analyses, common distinct bands were observed in samples from separate portions of the LN and intramuscular sarcoid lesions (Fig. 3B).

\section{Sequence Analysis of Common Bands}

To confirm whether the common band in different samples contained the same major sequence and to examine whether or not a common sequence motif existed in CDR3, DNA were eluted from the major common band in $\mathrm{V} \beta 3$ analysis in patients $1,3,4,5,7$, and 8. These DNA were subcloned, plated, and sequenced. Since such a clonal band is usually located within a smear pattern, several different sequences might be present within each eluted band. Accordingly, a minimum of 12 clones derived from each eluted band were sequenced to determine whether or not there was a dominant sequence. It was found that each band demonstrated a major sequence that was present in at least 8 of the 12 clones sequenced in every case. In each case tested, the common bands observed in different samples of the same patient gave the same major sequence. The protein sequences deduced from the DNA sequences are shown in Table 2. No common sequence motif was detected.

\section{Discussion}

Although the etiology of sarcoidosis is unknown, T-cell responses are thought to play a crucial role in its pathogenesis (2-9). However, the nature of $\mathrm{T}$ cells participating in the immune response of sarcoidosis is still not largely understood. As a result, an evaluation of the TCR repertoire and T-cell clonotypes of the involved $T$ cells may provide us with some clues to elucidate the role of $\mathrm{T}$ cells in this disease. Thus far, most TCR repertoire studies used BAL as materials (10-23). However, it is known that marked clonal expansion of $\mathrm{T}$ cells, probably due to activation by inhaled exogenous Ags, is observed even in BAL samples from normal healthy individuals (24). To minimize the effect of T-cell clones activated by Ags that were not related to the pathogenesis of sarcoidosis, we 
performed a RT-PCR-SSCP analysis using biopsy samples from intramuscular sarcoid lesions. $\mathrm{T}$ cells of the same clonality exist in different, widely separated sites in the intramuscular sarcoid lesions (Figs. 1A, 1B, 3). It is unlikely that such common clonotypes among the different portions of the same intramuscular sarcoid lesion reflect the residual or organspecific populations of $\mathrm{T}$ cells or reflect nonspecific activations. Rather they appear to expand in response to stimuli at the site of the disease.

We also performed a RT-PCR-SSCP analysis using biopsy samples from LN sarcoid lesions. Again, $\mathrm{T}$ cells of the same clonality were found to exist in different, widely separated sites in the LN sarcoid lesions (Figs. 2A, $2 \mathrm{~B})$. Some dominant bands in the scalene $\mathrm{LN}$ analyses may originate from the T-cell clones that expanded against unrelated Ags in the lung, exited from the lung, and then entered the scalene LN. However, in an early stage lung cancer patient without LN metastasis, the pretracheal LN, which was located very near to the lung, exhibited a smear pattern (Fig. 2C). In addition, axillary and inguinal LNs from two RA patients also showed smear patterns. As a result, although the presence of T-cell clones that expanded against the unrelated Ags in the lung cannot be ruled out, most of the distinct bands appeared to originate from the T-cell clones infiltrating into the LN sarcoid lesions.

Dominant T-cell clonotypes were sometimes present in PBMCs, as well as in two separate portions of LN sarcoid lesion. Naive T cells recirculate between the blood and lymph, with intermediate stops in the secondary lymphoid tissues. Activated T cells lose L-selectin that is involved in LN entry and increase expression of adhesion molecules on their surface. Cytokines such as interleukin- $1 \beta$ and tumor necrosis factor- $\alpha$ expressed in the sarcoid granuloma may induce the expression of selectins, integrin ligands, and immobilized chemokines on nearby vascular endothelial cells, which results in the recruitment of the previously activated $\mathrm{T}$ cells into the sarcoid lesions $(32,33)$. We, therefore, hypothesize that the $\mathrm{T}$ cells activated by disease-related Ags may tend to enter the sarcoid lesion and the frequencies of disease-related T cells are higher in LN sarcoid lesions than in PBMCs. To detect such difference of frequencies of expanded T-cell clones in our RT-PCR-SSCP analysis, cycles of PCR need to be adjusted.

Previous studies on TCR V gene repertoire usage focused on the limited or biased usage of certain subfamilies of $\alpha$-chain, $\beta$-chain, $\gamma$-chain, or $\delta$-chain in a subgroup of the patients (10-23). In such a subgroup, these restricted $V$ gene elements may certainly play an important role in the development of this disease. However, our results indicate that expanded $\mathrm{T}$ cells use a wider range of $\mathrm{V} \beta$ subfamilies. This may suggest that there are multiple immuneresponses to several different Ags. As tissue damaged by inflammation appears to further produce new Ags, not all the $\mathrm{T}$ cells accumulated in muscle sarcoid lesions are specific to disease-related Ags. In addition, when inflammation in sarcoid lesions progresses, Ag nonspecific activation and the expansion of $\mathrm{T}$ cells via several cytokines that lead to polyclonal activation of $\mathrm{B}$ cells are provoked $(34,35)$. It may, thus, be necessary to analyze the T-cell responses in early lesions, rather than in late lesions, to gain a better understanding of the etiology of sarcoidosis. On the other hand, when heterogeneous T-cell populations are cultured with purified protein derivatives, similar multiple patterns are obtained $(26,30)$. Although purified protein derivatives do not consist of a single molecule, this finding suggests that the multiple bands in our analysis might result from strong immune responses to a rather limited Ag complex.

Sarcoidosis is a multisystem disorder and thus the noncaseating granulomas can form in organs throughout the body. T cells specific to disease-related Ags may be present in sarcoid lesions in different organs. In two patients, we had a chance to analyze samples from sarcoid lesions in different organs (Fig. 3). In patient 4, we analyzed a TBLB sample, in addition to two samples from widely separated sites in the intramuscular sarcoid lesion. Although TBLB specimens, as BAL samples, may contain clonal $\mathrm{T}$ cells activated by irrelevant antigens, the bands derived from these irrelevant clones cannot be observed in an analysis of intramuscular sarcoid lesion and, thus, can be distinguished from the bands from disease-related clones. In $\mathrm{V} \beta 4,6,7,9-11,15$, and 20 analyses, common distinct bands were observed among these three samples. In patient 5, we analyzed two samples from separated sites in the intramuscular sarcoid lesion and those in the LN sarcoid lesion. In this case, common distinct bands were observed in the $\mathrm{V} \beta 2-4$ and 9 analyses. The presence of common T-cell clones in samples from different tissues in these 
two patients further supports the underlying Ag-specific mechanism in the pathogenesis of sarcoidosis. The further characterization of such clones may greatly help to better understand the pathogenesis of sarcoidosis, including the identification of the primary Ag responsible for the formation of sarcoid lesion, and may also help in the development of new therapies, such as vaccines against such $\mathrm{T}$ cells.

\section{Acknowledgements}

We would like to thank E. Kohno and M. Eto for their excellent technical assistance. These studies were supported in part by a grant from the Ministry of Education of Japan.

\section{References}

1. Thomas PD, Hunninghake GW. (1987) Current concepts of the pathogenesis of sarcoidosis. Am. Rev. Respir. Dis. 135: 747-760.

2. Crystal RG, Bitterman PB, Rennard SI, Hance AJ, Keogh BA. (1984) Interstitial lung diseases of unknown cause: disorders characterized by chronic inflammation of the lower respiratory tract. N. Engl. J. Med. 310: 235-244.

3. Hunninghake GW, Crystal RG. (1981) Pulmonary sarcoidosis: a disorder mediated by excess helper T-lymphocyte activity at sites of disease activity. N. Engl. J. Med. 305: 429-434.

4. Costabel U, Bross KJ, Ruhle KH, Lohr GW, Matthys H. (1985) Ia-like antigens on T-cells and their subpopulations in pulmonary sarcoidosis and in hypersensitivity pneumonitis: analysis of bronchoalveolar and blood lymphocytes. Am. Rev. Respir. Dis. 131: 337-342.

5. Konishi K, Moller DR, Saltini C, Kirby M, Crystal RG. (1988) Spontaneous expression of the interleukin 2 receptor gene and presence of functional interleukin 2 receptors on $\mathrm{T}$ lymphocytes in the blood of individuals with active pulmonary sarcoidosis. J. Clin. Invest. 82: 775-781.

6. Saltini C, Hemler ME, Crystal RG. (1988) T lymphocytes compartmentalized on the epithelial cell surface of the lower respiratory tract express the very late activation antigen complex VLA-1. Clin. Immunol. Immunopathol. 46: 221-233.

7. Dannenberg AM Jr. (1982) Pathogenesis of pulmonary tuberculosis. Am. Rev. Respir. Dis. 125: 25-29.

8. Bloom BR, Mehra V. (1984) Immunological unresponsiveness in leprosy. Immunol. Rev. 80: 5-28.

9. Rossman MD, Kern JA, Elias JA, et al. (1988) Proliferative response of bronchoalveolar lymphocytes to beryllium. Ann. Intern. Med. 108: 687-693.
10. Moller DR, Kazuki K, Martha K, Bruno B, Crystal RG. (1988) Bias toward use of a specific $\mathrm{T}$ cell receptor $\beta$-chain variable region in a subgroup of individuals with sarcoidosis. J. Clin. Invest. 82: 1183-1191.

11. Tamura N, Holroyd KJ, Banks T, Kirby M, Okayama H, Crystal RG. (1990) Diversity in junctional sequences associated with the common human $\mathrm{V} \gamma 9$ and $\mathrm{V} \delta 2$ gene segments in normal blood and lung compared with the limited diversity in a granulomatous disease. J. Exp. Med. 172: 169-181.

12. Balibi B, Moller DR, Kirby M, Holroyd KJ, Crystal RG. (1990) Increased numbers of T lymphocytes with $\gamma \delta$-positive antigen receptors in a subgroups of individuals with pulmonary sarcoidosis. J. Clin. Invest. 85: 1353-1361.

13. Grunewald J, Janson CH, Eklund A, et al. (1992) Restricted V $\alpha 2.3$ gene usage by $\mathrm{CD}^{+} \mathrm{T}$ lymphocytes in bronchoalveolar lavage fluid from sarcoidosis patients correlates with HLADR3. Eur. J. Immunol. 22: 129-135.

14. Forrester JM, Newman LS, Wang Y, King TE Jr, Kotzin BL. (1993) Clonal expansion of lung $\mathrm{V} \delta 1^{+} \mathrm{T}$ cells in pulmonary sarcoidosis. J. Clin. Invest. 91: 292-300.

15. Forman JP, Silver R, Ankins M, et al. (1992) Preferential expression of a limited number of T-cell receptor variable $\beta$-genes in active pulmonary sarcoidosis (abstract). Am. Rev. Resp. Dis. 145: A414.

16. Forrester JM, Wang Y, Loveless J, Newman LS, King TE, Kotzin BL. (1992) Preferential T cell receptor beta chain variable gene usage in pulmonary sarcoidosis (abstract). Am. Rev. Resp. Dis. 145: A414.

17. Jones CM, Lake RA, Wijeyekoon JB, Mitchell DM, du Bois RM, O'Hehir RE. (1996) Oligoclonal $\mathrm{V}$ gene usage by $\mathrm{T}$ lymphocytes in bronchoalveolar lavage fluid from sarcoidosis patients. Am. J. Respir. Cell Mol. Biol. 14: 470-477.

18. Trentin L, Zambello R, Facco M, et al. (1997) Selection of $\mathrm{T}$ lymphocytes bearing limited TCR$\mathrm{V} \beta$ regions in the lung of hypersensitivity pneumonitis and sarcoidosis. Am. J. Respir. Crit. Care Med. 155: 587-596.

19. Grunewald J, Olerup O, Persson U, Öhrn MB, Wigzell H, Eklund A. (1994) T-cell receptor variable region gene usage by $\mathrm{CD}^{+}$and $\mathrm{CD} 8^{+}$ $\mathrm{T}$ cells in bronchoalveolar lavage fluid and peripheral blood of sarcoidosis patients. Proc. Natl. Acad. Sci. U.S.A. 91: 4965-4969.

20. Grunewald J, Hultman T, Bucht A, Eklund A, Wigzell H. (1995) Restricted usage of T cell receptor $\mathrm{V} \alpha / \mathrm{J} \alpha$ gene segments with different nucleotide but identical amino acid sequences in HLA-DR3 ${ }^{+}$ sarcoidosis patients. Mol. Med. 1: 287-296.

21. Usui Y, Kohsaka H, Eishi Y, Saito I, Marumo F, Miyasaka N. (1996) Shared amino acid motifs in T-cell receptor $\beta$ junctional regions of bronchoalveolar $\mathrm{T}$ cells in patients with pulmonary sarcoidosis. Am. J. Respir. Crit. Care Med. 154: 50-56. 
22. Wilsher ML, Hallowes M, Birchall NM. (1996) Gamma/delta cells in tissue from patients with sarcoidosis. Thorax 51: 1123-1126.

23. Gruber R, Pforte A, Beer B, Riethmüller G. (1996) Determination of gamma/delta and other T-lymphocyte subsets in bronchoalveolar lavage fluid and peripheral blood from patients with sarcoidosis and idiopathic fibrosis of the lung. APMIS 104: 199-205.

24. Dohi M, Yamamoto K, Masuko K, et al. (1994) Accumulation of multiple $\mathrm{T}$ cell clonotypes in lungs of healthy individuals and patients with pulmonary sarcoidosis. J. Immunol. 152: 1983-1988.

25. Choi Y, Kotzin B, Herron L, Callahan J, Marrack P, Kappler J. (1989) Interaction of Staphylococcus aureus toxin superantigens with human T cells. Proc. Natl. Acad. Sci. U.S.A. 86: 8941-8945.

26. Yamamoto $K$, Sakoda $H$, Nakajima $T$, et al. (1992) Accumulation of multiple $\mathrm{T}$ cell clonotypes in the synovial lesions of patients with rheumatoid arthritis revealed by a novel clonality analysis. Int. Immunol. 4: 1219-1223.

27. Yamamoto K, Masuko K, Takahashi S, et al. (1995) Accumulation of distinct $\mathrm{T}$ cell clonotypes in human solid tumors. J. Immunol. 154: 1804-1809.
28. Masuko K, Kato S, Hagihara M, et al. (1996) Stable clonal expansion of $\mathrm{T}$ cells induced by bone marrow transplantation. Blood 87: 789-799.

29. Ikeda Y, Masuko K, Nakai Y, et al. (1996) High frequencies of identical $T$ cell clonotypes in synovial tissues of rheumatoid arthritis patients suggest the occurrence of common antigen-driven immune responses. Arthritis Rheum. 39: 446-453.

30. Masuko K, Kato T, Ikeda Y, et al. (1994) Dynamic changes of accumulated $T$ cell clonotypes during antigenic stimulation in vivo and in vitro. Int. Immunol. 6: 1959-1966.

31. Nakajima A, Kodama T, Yazaki Y, et al. (1996) Specific clonal $\mathrm{T}$ cell accumulation in intestinal lesions of Crohn's disease. J. Immunol. 157: 5683-5688.

32. Bergeron A, Bonay $M$, Kambouchner $M$, et al. (1997) Cytokine patterns in tuberculous and sarcoid granulomas. J. Immunol. 159: 3034-3043.

33. Mondino A, Khoruts A, Jenkins MK. (1996) The anatomy of T-cell activation and tolerance. Proc. Natl. Acad. Sci. U.S.A. 93: 2245-2252.

34. Fink JN, Kelly KJ. (1992) Immunologic aspects of granulomatous and interstitial lung diseases and of cystic fibrosis. JAMA 268: 2874-2881.

35. Crystal RG, Bitterman PB, Rennard SI. (1984) Interstitial lung diseases of unknown cause. N. Engl. J. Med. 310: 154-166, 235-244. 